\title{
Effect of epidural analgesia in patients with traumatic rib fractures: a systematic review and meta-analysis of randomized controlled trials
}

\section{L'effet de l'analgésie péridurale chez les patients présentant des fractures de côtes multiples: une revue systématique et une méta-analyse des essais randomisés contrôlés}

\author{
François M. Carrier, MD · Alexis F. Turgeon, MD • Pierre C. Nicole, MD • \\ Claude A. Trépanier, MD · Dean A. Fergusson, PhD · Daniel Thauvette, MD · \\ Martin R. Lessard, MD
}

Received: 28 August 2008/Revised: 3 November 2008/ Accepted: 5 January 2009/Published online: 11 February 2009

(C) Canadian Anesthesiologists' Society 2009

\begin{abstract}
Purpose A consensus group recently proposed epidural analgesia as the optimal analgesic modality for patients with multiple traumatic rib fractures. However, its beneficial effects are not consistently recognized in the literature. We performed a systematic review and a meta-analysis of randomized controlled trials (RCT) of epidural analgesia in adult patients with traumatic rib fractures.

Methods A systematic search strategy was applied to MEDLINE, EMBASE, the Cochrane Library and to the annual meeting of relevant societies (up to July 2008). All randomized controlled trials comparing epidural analgesia with other analgesic modalities in adult patients with traumatic rib fractures were included. Primary outcomes
\end{abstract}

Abstract presentation: Presented in part at the Residents' Competition at the 62nd Annual Meeting of the Canadian Anesthesiologists' Society, Calgary, Alberta, Canada, June 22-26, 2007.

F. M. Carrier, MD · A. F. Turgeon, MD ( $₫)$.

P. C. Nicole, MD - C. A. Trépanier, MD - M. R. Lessard, MD

Department of Anesthesiology, Hôpital de l'Enfant-Jésus,

Université Laval, 1401, 18ème rue, Quebec, QC G1J 1Z4,

Canada

e-mail: alexis.turgeon@fmed.ulaval.ca

F. M. Carrier, MD - A. F. Turgeon, MD - D. Thauvette, MD .

M. R. Lessard, MD

Division of Critical Care Medicine, Hôpital de l'Enfant-Jésus,

Université Laval, Quebec, QC, Canada

A. F. Turgeon, MD

Axe Traumatologie - Urgence - Soins Intensifs du Centre de

Recherche du CHA, Hôpital de l'Enfant-Jésus, Université Laval,

Quebec, QC, Canada were mortality, ICU length of stay (LOS), hospital LOS and duration of mechanical ventilation.

Results Eight studies (232 patients) met eligibility criteria. Epidural analgesia did not significantly affect mortality (odds ratio [OR] 1.6, 95\% CI, 0.3, 9.3, 3 studies, $n=89$ ), ICU LOS (weighted mean difference [WMD] -3.7 days, 95\% CI, -11.4, 4.0, 4 studies, $n=135)$, hospital LOS (WMD -6.7, 95\% CI, -19.8, 6.4, 4 studies, $n=140$ ) or duration of mechanical ventilation (WMD 7.5, 95\% CI, $-16.3,1.2,3$ studies, $n=101)$. Duration of mechanical ventilation was decreased when only studies using thoracic epidural analgesia with local anesthetics were evaluated (WMD -4.2, 95\% CI, -5.5, -2.9, 2 studies, $n=73$ ). However, hypotension was significantly associated with the use of thoracic epidural analgesia with local anesthetics (OR 13.76, 95\% CI, 2.89, 65.51, 3 studies, $n=99$ ).

D. A. Fergusson, $\mathrm{PhD}$

Clinical Epidemiology Unit, Ottawa Health Research Institute,

Ottawa, Canada

D. Thauvette, MD

Department of Surgery, Hôpital de l'Enfant-Jésus, Université Laval, Quebec, QC, Canada 
Conclusions No significant benefit of epidural analgesia on mortality, ICU and hospital LOS was observed compared to other analgesic modalities in adult patients with traumatic rib fractures. However, there may be a benefit on the duration of mechanical ventilation with the use of thoracic epidural analgesia with local anesthetics. Further research is required to evaluate the benefits and harms of epidural analgesia in this population before being considered as a standard of care therapy.

\section{Résumé}

Objectif Un groupe de consensus a récemment proposé l'analgésie péridurale en tant que modalité analgésique optimale pour les patients présentant des fractures de côtes multiples. Toutefois, les effets bénéfiques de l'analgésie péridurale ne sont pas clairement reconnus dans la littérature. L'objectif de cette étude était d'évaluer l'efficacité de l'analgésie péridurale dans cette population par une revue systématique et une méta-analyse des essais randomisés contrôlés portant sur l'analgésie péridurale chez. les patients adultes présentant des fractures traumatiques de côtes.

Méthode Une recherche systématique a été effectuée dans les bases de données MEDLINE, EMBASE, the Cochrane Library et dans les résumés de congrès médicaux pertinents (jusqu'à juillet 2008). Tous les essais cliniques randomisés comparant l'analgésie péridurale à une autre modalité analgésique chez les adultes avec fractures de côtes multiples ont été inclus. Les critères d'évaluation principaux étaient la mortalité, la durée de séjour à l'hôpital et à l'unité de soins intensifs (USI) ainsi que la durée de ventilation mécanique.

Résultats Huit études $(n=232)$ ont été retenues et analysées. L'analgésie péridurale n'était pas associée à une diminution significative de la mortalité (rapport de cotes [RC] 1,6, IC $95 \%(0,3,9,3) 3$ études, $n=89)$, ni à une diminution de la durée de séjour à l'USI (différence pondérée des moyennes [DPM] -3,7 jours, IC $95 \%(-11,4$, 4,0), 4 études, $n=135$ ) ou à l'hôpital (DPM-6,7 jours, $I_{95} \%(-19,8,6,4), 4$ études, $\left.n=140\right)$, ni à une diminution de la durée de ventilation mécanique (DPM -7,5 jours, $I_{95} \%(-16,3,1,2), 3$ études, $\left.n=101\right)$. Par contre, la durée de ventilation mécanique était significativement diminuée lorsque seules les études utilisant des péridurales thoraciques avec anesthésiques locaux étaient analysées (DPM -4,2 jours, $I C_{95} \%(-5,5,-2,9)$, 3 études, $n=73$ ). L'analgésie péridurale thoracique avec anesthésiques locaux était aussi associée à une plus grande incidence d'hypotension artérielle ( $R C$ 13,76, IC $95 \%$ (2,89, 65,51), 3 études, $n=99$ ).

Conclusion Chez les adultes avec fractures de côtes multiples, aucun bienfait significatif de l'analgésie péridurale sur la mortalité, la durée de séjour à l'hôpital et à l'USI n'a été observé. Néanmoins, l'utilisation de la péridurale thoracique avec anesthésiques locaux pourrait peut-être diminuer la durée de ventilation mécanique. Des données supplémentaires sont nécessaires afin d'évaluer les bienfaits et effets délétères de l'analgésie péridurale dans cette population avant de favoriser son utilisation étendue comme standard de soins.

Thoracic trauma is the second most frequent injury found in non-intentional injury related deaths in the USA. ${ }^{1,2}$ In 2004, 764,000 patients presented to an emergency department in the USA for a thoracic injury. ${ }^{1}$ The prevalence of rib fractures is from 4 to $10 \%$ amongst trauma patients requiring hospital admission, ${ }^{2,3}$ with mortality and pulmonary complication rates ranging from 3 to $13 \%$ and from 16 to $60 \%$, respectively. ${ }^{1-7}$ Pain is recognized as a contributing factor for most of this associated morbidity, ${ }^{6-9}$ and analgesia is a core intervention in managing these patients. ${ }^{5,7}$ Multiple analgesic modalities have been used in patients with rib fractures, ${ }^{4}$ such as oral analgesics, ${ }^{10}$ intravenous opioids, ${ }^{7,11}$ patient-controlled opioid analgesia, ${ }^{12}$ interpleural blocks, ${ }^{11}$ intercostal blocks, ${ }^{11,13}$ paravertebral blocks, ${ }^{11,14}$ and epidural analgesia. $6,7,10,11,15,16$ Recent studies and metaanalyses have suggested that epidural analgesia reduces morbidity after major abdominal, ${ }^{17-20}$ vascular, ${ }^{18,20,21}$ and thoracic surgeries, ${ }^{17,18,20}$ overcoming the potential risk of complications associated with this technique., ${ }^{48-24}$ In trauma patients with rib fractures, retrospective studies showed inconsistent benefits of epidural analgesia compared to other analgesic modalities. ${ }^{4,6,10,15,16}$ The conclusion of a recent narrative review on pain management in this population stated that, based on available data, no single analgesic modality could be recommended. ${ }^{11}$ However, recent published guidelines state that epidural analgesia is the preferred analgesic modality in patients with multiple rib fractures. $^{25}$ No meta-analysis on this topic has yet been completed. On the other hand, epidural analgesia is not a benign procedure and has potential major complications, such as hematoma and abscess in the epidural space. Despite a very low incidence, these serious adverse events can be catastrophic. $^{26,27}$

Consequently, since traumatic rib fractures are associated with significant morbidity and contradictory evidence exists in regards to pain management in this specific population, we conducted a systematic review of the literature evaluating the effect of epidural analgesia compared to other analgesic modalities in the management of adult patients with traumatic rib fractures. 


\section{Methods}

Search strategy

An electronic search was performed using MEDLINE, EMBASE, and The Cochrane Register of Controlled Trials from inception to July 2008. The text words used for epidural analgesia were "epidural analgesia", "epidural anesthesia", "analgesia", "epidural catheter", "conduction anesthesia", "epidural space", and "pain management". The text words "analgesia epidural", "anesthesia epidural", "analgesia", "anesthesia conduction", and "epidural space" were used as MeSH terms in MEDLINE and The Cochrane Register of Controlled Trials. "Analgesia" and "epidural anesthesia" were used as EMTREE keywords in EMBASE. Text words used for thoracic trauma were "chest trauma", "thoracic trauma", "thoracic injuries", "flail chest", and "rib fractures". "Rib fractures" and "flail chest" were used as MeSH terms and EMTREE keywords in the three databases. "Thoracic injuries" was used as a MeSH term in MEDLINE and The Cochrane Register of Controlled Trials, and "thorax injury" was used as an EMTREE keyword in EMBASE.

Two authors, FMC and PCN, reviewed all citations to identify relevant studies. References of retrieved articles and review articles were searched for relevant citations. Annual meeting supplements of the following medical organizations were also searched for relevant abstracts available from 2000 to 2008 on their websites: Canadian Anesthesiologists' Society, American Society of Anesthesiologists, American Society of Regional Anesthesia and Pain Medicine, Society of Critical Care Medicine, American College of Chest Physicians, American Thoracic Society, American Association for Thoracic Surgery, American Association for the Surgeons of Trauma, and the International Symposium of Intensive Care and Emergency Medicine.

\section{Study eligibility}

All randomised controlled studies conducted in adult patients with traumatic rib fractures evaluating the effect of epidural analgesia compared to any other analgesic modalities were included. The primary outcomes were mortality (any time), Intensive Care Unit (ICU) length of stay (LOS), hospital LOS, and duration of mechanical ventilation. The following were considered as secondary outcomes: nosocomial pneumonia, quality of pain control, and respiratory function. Potential adverse effects, such as hypotension, nausea and vomiting, local infection, epidural abscess, and epidural hematoma, were also sought and evaluated. Studies were considered as being conducted in adults when more than $80 \%$ of the patients were older than 18 years of age.
Eligibility was not restricted by language or type of publication (letter, abstract, book chapter, or full manuscript).

Data abstraction

A standardized data abstraction form was developed and used. Two authors, FMC and AFT, independently reviewed relevant studies and extracted data. In cases where a unanimous decision could not be reached, a third party, PCN, was consulted. A translator was consulted for studies published in a foreign language. When required, the corresponding author of an included study was contacted, via either e-mail or standard mail, to clarify the methodology or to provide additional data.

\section{Validity assessment}

The Jadad scale was used to assess the quality of methodology. This scale (from 0 to 5) provides scoring for randomization (0-2), double blinding (0-2), and withdrawals (1). A score of $\geq 3$ was considered to be of high quality methodology. ${ }^{28}$ Other methodological aspects were also evaluated, such as concealment of randomization, blinding of outcomes to evaluators, intention-to-treat analysis, and the number of centres involved. ${ }^{29}$

\section{Data synthesis}

DerSimonian-Laird random effects models were used to synthesize data. ${ }^{30}$ Fixed effects models using the Peto method were used to analyze sparse data, such as mortality. A constant continuity correction (0.5) was used in the case of a zero event in one or two arms. When data synthesis was inappropriate, data were analyzed in a qualitative manner. Analyses were conducted using Review Manager 4.2.10 (The Cochrane Collaboration, 2007) and Comprehensive Meta-Analysis 2.2 (Biostat, 2006). Continuous measures of effect are expressed as weighted mean differences (WMD) with 95\% confidence intervals (95\% CI). Dichotomous measures of effect are presented as odds ratio (OR) with $95 \%$ CI. An OR $<1$ suggests an increased benefit of the outcome of interest in the epidural group compared to the control group. Statistical tests for heterogeneity were carried out (with $P$-value $<0.10$ indicating significance), and $I^{2}$ measures of consistency across trials were performed. ${ }^{31}$ The following hypotheses were applied to explain heterogeneity: the quality of methodology in the primary studies, the patients' ages, the severity of the underlying disease, the severity of trauma, the differences in the treatment regimen (thoracic epidural analgesia using local anesthetics vs epidural analgesia using opioids), or simply chance. When possible, a series of sensitivity analyses based on study characteristics were performed to 
explore heterogeneity as well as to evaluate the strength of the findings.

\section{Results}

Search results

A total of 718 citations were retrieved from the systematic search: 683 from the electronic search, 33 from reference screening, and two from annual meeting websites (Fig. 1). From these citations, 12 potentially eligible randomized controlled studies were identified, but four were excluded because of non-randomization for the therapeutic regimen, ${ }^{32}$ data invalidated by the author (did not perform the study), ${ }^{33}$ or absence of a control group. ${ }^{34,35}$ Therefore, eight studies, including a total of 232 patients, met inclusion criteria for this systematic review (Table 1). ${ }^{36-43}$

\section{Study characteristics}

Seven studies were published in English ${ }^{36-40,42,43}$ and one in Turkish. ${ }^{41}$ Six trials were conducted in North America $^{36-39,42,43}$ and two were conducted in Asia. ${ }^{40,41}$ Seven were presented as full publications ${ }^{37-43}$ and one was presented as an abstract. ${ }^{36}$

The eight studies only included patients who were older than 18 years of age with multiple rib fractures. One study only enrolled patients who were suffering from flail chest, ${ }^{41}$ while three other studies only included patients with unilateral rib fractures. ${ }^{39,40,43}$ Two studies only included patients under mechanical ventilation. ${ }^{41,43}$ In all studies, patients had a normal level of consciousness. ${ }^{36-43}$ Exclusion criteria were mentioned in six studies: spinal cord injury or spine fracture, ${ }^{36,37,42}$ need for mechanical ventilation, ${ }^{40}$ or contraindications to epidural catheter insertion, such as hemodynamic instability and coagulopathy. ${ }^{36-38}$

Three studies compared the effect of thoracic epidural analgesia (TEA) with local anesthetics to parenteral opioids, ${ }^{37,38,41}$ two studies compared TEA with local anesthetics to interpleural analgesia, ${ }^{39,40}$ and three studies compared epidural analgesia with opioids to parenteral opioids. $^{36,42,43}$

Five studies reported data on at least one of the primary outcomes: mortality $(n=4),{ }^{37-40}$ ICU LOS $(n=5),{ }^{36-38,41,43}$ hospital LOS $(n=5),{ }^{36-38,42,43}$ and duration of mechanical ventilation $(n=3)^{37,41,43}$ (Table 2). The number of studies reporting secondary outcomes were: quality of pain control $(n=5)^{36,38-40,42}$ (Table 3), nosocomial pneumonia $(n=1),{ }^{37}$ and respiratory function $(n=5) .^{38-40,42,43}$

\section{Supplemental information}

Clarification on the outcome data and the quality of methodology of six studies was obtained from the
Fig. 1 Results of search strategy

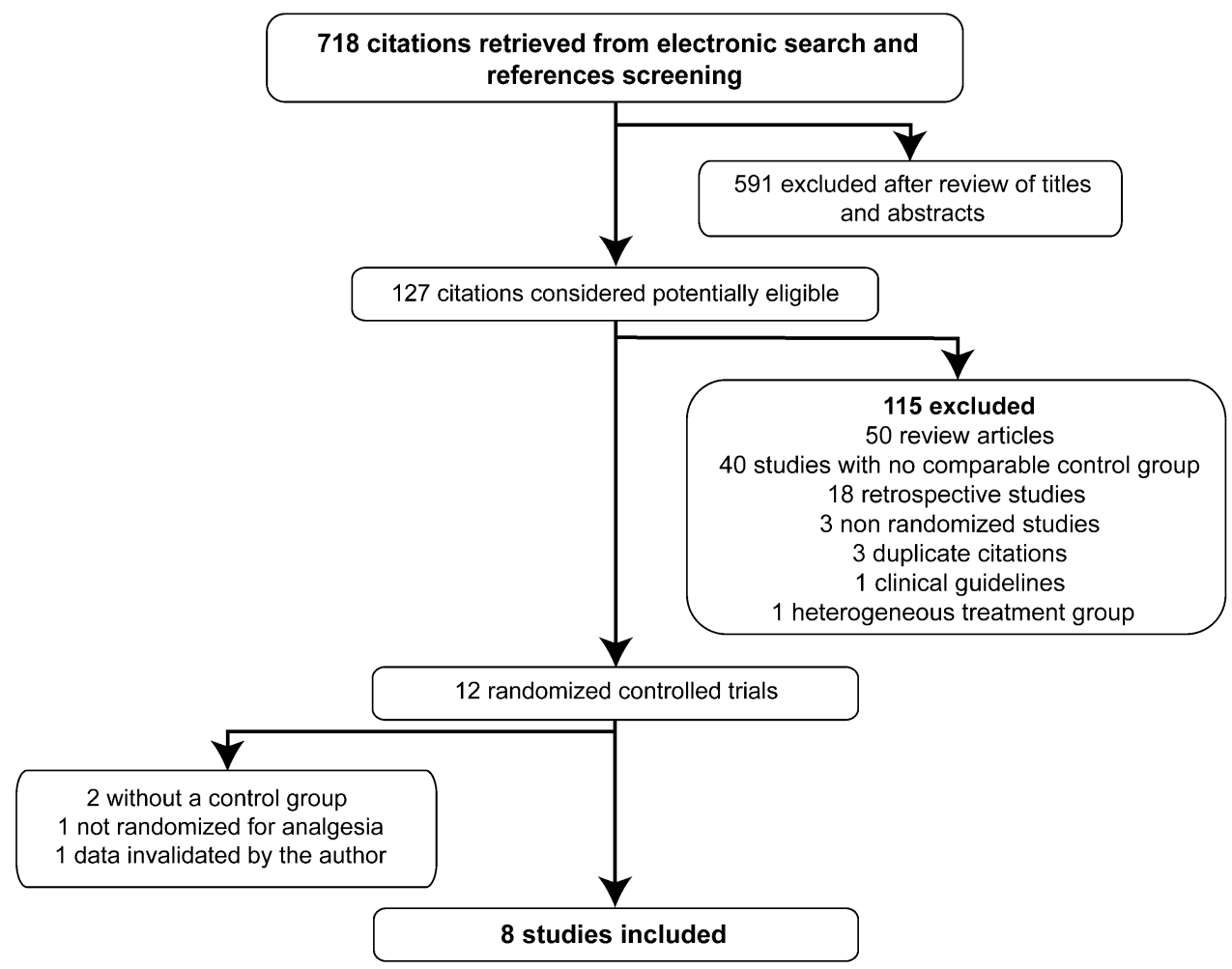




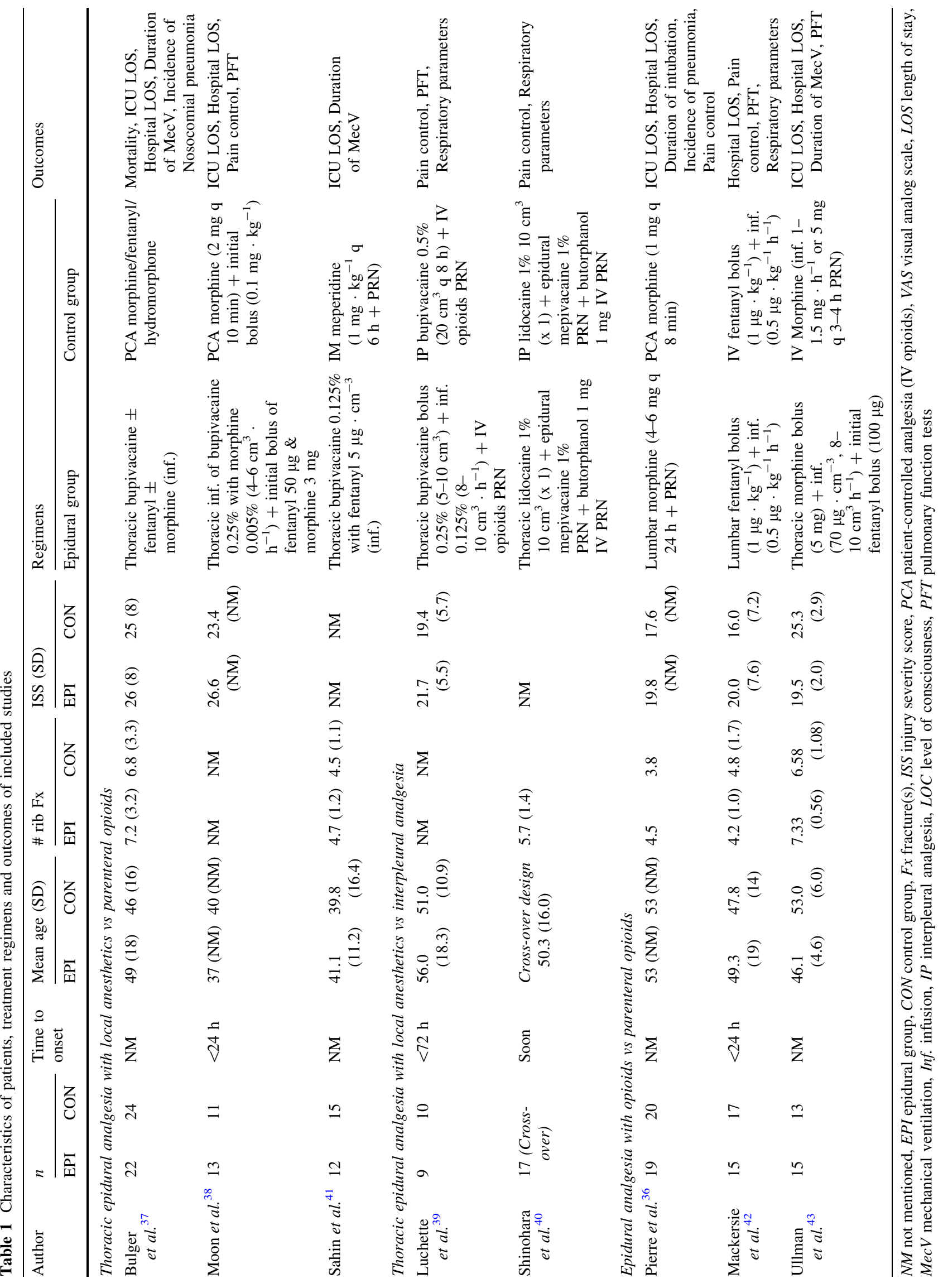


Table 2 Primary outcome measures

\begin{tabular}{|c|c|c|c|c|c|c|c|c|}
\hline \multirow[t]{2}{*}{ Author } & \multicolumn{2}{|c|}{ Mortality (\%) } & \multicolumn{2}{|c|}{ ICU LOS (days) } & \multicolumn{2}{|c|}{ Hospital LOS (days) } & \multicolumn{2}{|c|}{ Duration of mechanical ventilation (days) } \\
\hline & $\begin{array}{l}\text { Epidural } \\
\text { group }\end{array}$ & $\begin{array}{l}\text { Control } \\
\text { group }\end{array}$ & $\begin{array}{l}\text { Epidural } \\
\text { group }\end{array}$ & $\begin{array}{l}\text { Control } \\
\text { group }\end{array}$ & $\begin{array}{l}\text { Epidural } \\
\text { group }\end{array}$ & $\begin{array}{l}\text { Control } \\
\text { group }\end{array}$ & $\begin{array}{l}\text { Epidural } \\
\text { group }\end{array}$ & $\begin{array}{l}\text { Control } \\
\text { group }\end{array}$ \\
\hline Pierre et al. ${ }^{36}$ & NA & NA & 3.1 & $6.6^{\mathrm{a}}$ & 10.8 & $15.9^{\mathrm{a}}$ & NA & NA \\
\hline Bulger et al. ${ }^{37}$ & 9.1 & 4.2 & $10 \pm 15$ & $12 \pm 26$ & $18 \pm 16$ & $16 \pm 13$ & $8 \pm 16$ & $9 \pm 26^{\mathrm{b}}$ \\
\hline Moon et al. ${ }^{38}$ & 0 & 0 & $4.3 \pm 4.0$ & $4.1 \pm 5.1$ & $11 \pm 6.1$ & $9.6 \pm 6.2$ & NA & NA \\
\hline Luchette et $a l .{ }^{39}$ & 0 & 0 & NA & NA & NA & NA & NA & NA \\
\hline Shinohara et al. ${ }^{40}$ & 0 & 0 & NA & NA & NA & NA & NA & NA \\
\hline Sahin et al. $^{41}$ & NA & NA & $10.2 \pm 2.1$ & $9.8 \pm 3.2$ & NA & NA & $1.3 \pm 0.8$ & $5.5 \pm 2.4^{\mathrm{c}}$ \\
\hline Mackersie et al. ${ }^{42}$ & NA & NA & NA & NA & $8.7 \pm 4.2$ & $7.1 \pm 6.2$ & NA & NA \\
\hline Ullman et al. ${ }^{43}$ & NA & NA & $5.9 \pm 1.4$ & $18.7 \pm 5.2^{\mathrm{d}}$ & $14.9 \pm 2.2$ & $47.7 \pm 14.7^{\mathrm{d}}$ & $3.1 \pm 1.3$ & $18.2 \pm 8.1^{\mathrm{d}}$ \\
\hline
\end{tabular}

${ }^{a}$ Statistically significant, but $P$ value not mentioned

b When adjusted for pulmonary contusions, IRR (incident rate ratio) $=2.0(1.6-2.6)$ with $P<0.001$ in favour of epidural group

${ }^{c} P<0.001$

${ }^{\mathrm{d}} P<0.05$

$N A$ not available, ICU intensive care unit, $L O S$ length of stay

corresponding authors. $^{33,36-40}$ Additional data on 17 new patients who were enrolled following publication were obtained for one abstract. ${ }^{36}$ However, since we could not obtain any standard deviation of the outcomes of interest, this study could not be included in the pooled analyses. ${ }^{36}$ For another study, standard deviations for ICU LOS and hospital LOS were calculated from raw data provided by the corresponding author. ${ }^{38}$

\section{Validity assessment}

Of the four studies considered to be of high methodologolgical quality, ${ }^{37-40}$ only two reported data on one of our primary outcomes $^{37,38}$ (Table 4). Attrition information was available for five studies: no drop-outs were observed in three studies, ${ }^{37,39,40}$ and drop-outs were excluded from the analyses in two studies. ${ }^{36,38}$ Appropriate method of allocation concealment was confirmed in four studies. ${ }^{37-40}$ Only one study mentioned cross-over between groups, and it was also the only study using intention-to-treat analyses. ${ }^{37}$ All studies were single centre studies.

Primary outcomes

\section{Mortality}

Among the four studies that reported data on mortality, only three were parallel group studies where mortality could be attributed to the intervention. ${ }^{37-39}$ No significant effect on mortality was observed with the use of epidural analgesia compared to other analgesic modalities (89 patients, $\quad \mathrm{OR}=1.6, \quad 95 \% \quad \mathrm{CI} \quad[0.3,9.3], \quad I^{2}=0.0 \%$ $[P=0.63])$ (Fig. 2).

\section{ICU length of stay}

No statistically significant reduction in ICU LOS was observed with the use of epidural analgesia compared to other analgesic modalities (125 patients, WMD -3.72, 95\% CI $\left.[-11.43,3.99], I^{2}=94.8 \%[P=0.34]\right)$. Again, pooled data of all studies using TEA with local anesthetics compared to parenteral opioids $(n=3)$ did not show significant reduction in ICU LOS (97 patients, WMD 0.31, $95 \%$ CI $\left.[-1.44,2.05], I^{2}=0 \%[P=0.73]\right),{ }^{37,38,41}$ similarly with pooled data from studies of high quality methodology $(n=2)$ (70 patients, WMD $0.01,95 \%$ CI $\left.[-3.54,3.57], I^{2}=0 \%[P=0.99]\right)^{37,38}$ (Fig. 2).

\section{Hospital length of stay}

No statistically significant reduction in hospital LOS was observed with the use of epidural analgesia compared to other analgesic modalities (130 patients, WMD -6.68, $95 \%$ CI $\left.[-19.76,6.40], I^{2}=95.2 \% \quad[P=0.32]\right)$. Even when only pooled data of studies using TEA with local anesthetics compared to parenteral opioids were analyzed $(n=2)$, no significant reduction was observed (70 patients, WMD $1.55, \quad 95 \% \quad$ CI $\quad[-2.72, \quad 5.82], \quad I^{2}=0 \%$ $[P=0.48])^{37,38}$ (Fig. 2). These last two studies were also of high quality methodology.

\section{Duration of mechanical ventilation}

When the data of three studies were pooled, no statistically significant reduction of duration of mechanical ventilation was observed (101 patients, WMD $-7.51,95 \%$ CI $\left.[-16.25,1.23], I^{2}=90.8 \%[P=0.09]\right) .{ }^{37,41,43}$ However, 


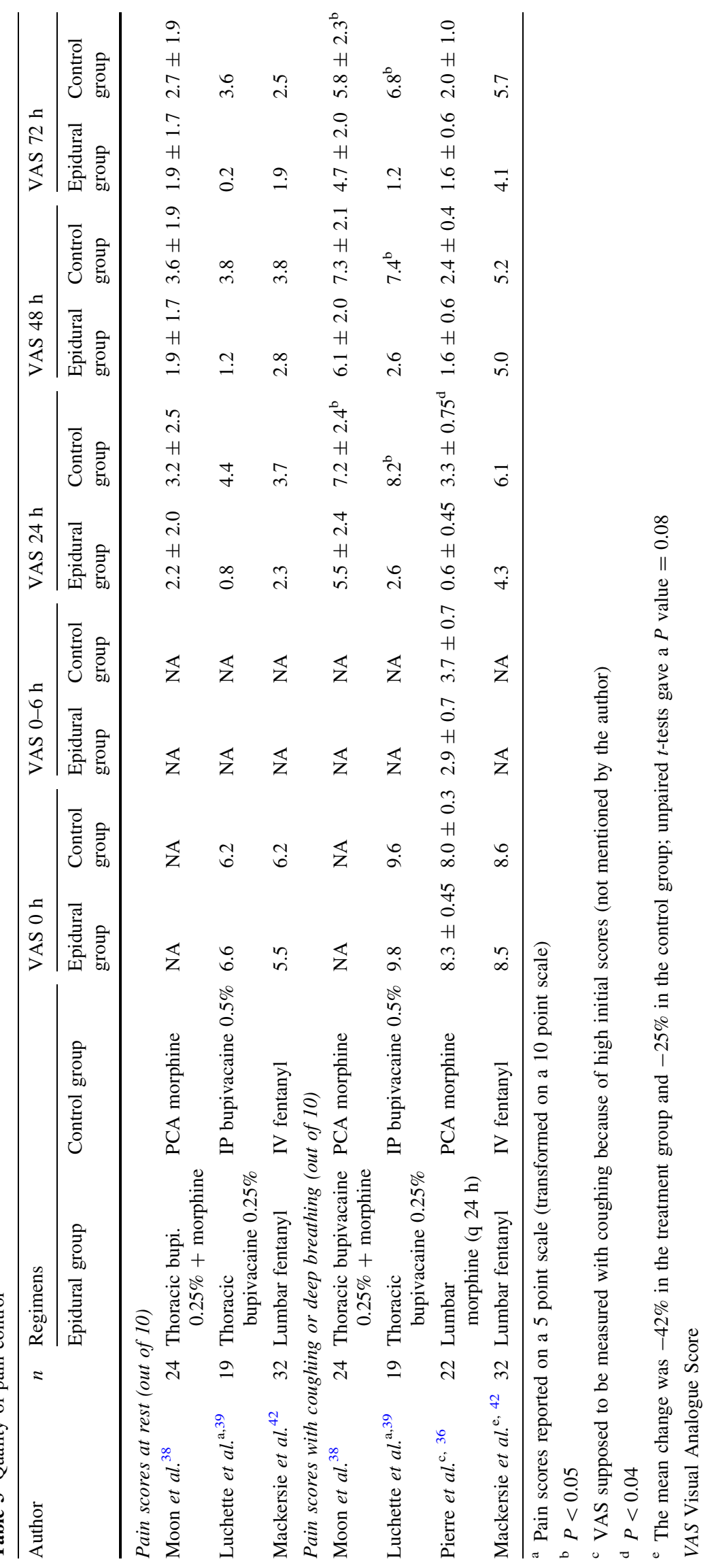




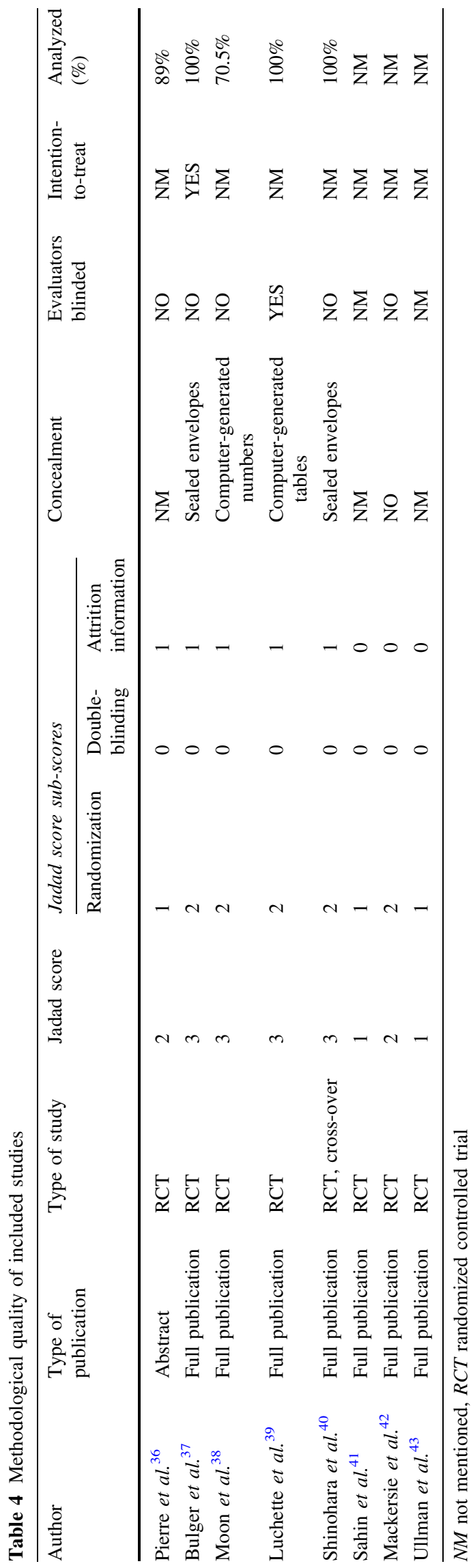

when only the results from studies using TEA with local anesthetics compared to parenteral opioids were pooled $(n=2)$, the duration of mechanical ventilation was significantly reduced by 4.17 days (73 patients, WMD -4.17 , 95\% CI $\left.[-5.45,-2.88], I^{2}=0 \%[P<0.01]\right)^{37,41}$ (Fig. 2).

Secondary outcomes

For all secondary outcomes, data synthesis and metaanalysis were not possible due to missing data on either standard deviation of the mean or on heterogeneous outcome measures.

\section{Nosocomial pneumonia}

In one study (46 patients), the incidence of nosocomial pneumonia was reduced by epidural analgesia compared to parenteral opioids. ${ }^{37}$ When adjusted for pulmonary contusions, flail chest, presence of chest tubes, and APACHE II scores, the OR for pneumonia in the parenteral opioids group was 6.0 (95\% CI [1.0-35], $[P=0.05]$ ), as presented by the authors in their manuscript. Information on how the analysis was adjusted could not be obtained.

\section{Pain control}

Four studies reported pain scores either at rest or with coughing or deep breathing ${ }^{36,38,39,42}$ (Table 3). The pain scores in one additional study were reported on a different categorical pain scale, which precluded comparison with other studies. ${ }^{40}$ Pain at rest, at 24,48 , and $72 \mathrm{~h}$, was not significantly reduced by epidural analgesia compared to other analgesic modalities in any study. ${ }^{38,39,42}$ However, statistically significant improvement in pain control was observed with cough or deep breathing in three studies. $36,38,39$

\section{Respiratory function}

Vital capacity was not altered by epidural analgesia. ${ }^{39,42,43}$ In three studies, there was no difference between the maximal inspiratory pressure with epidural analgesia and with other analgesic modalities at 24,48 , and $72 \mathrm{~h}^{38,39,42}$; however, statistical significance in one study was only observed at $72 \mathrm{~h} .{ }^{38}$ In three studies, the tidal volume reported during unassisted breathing ${ }^{38,39,43}$ was larger with epidural analgesia. No statistically significant difference in respiratory rate, $\mathrm{PaO}_{2}$, and $\mathrm{PaCO}_{2}$ were observed in three studies. ${ }^{40,42,43}$

\section{Adverse events}

Five studies reported adverse events, ${ }^{37-39,42,43}$ two studies reported none, ${ }^{36,40}$ and one study did not report adverse events $^{41}$ (Table 5). Compared to other analgesic 


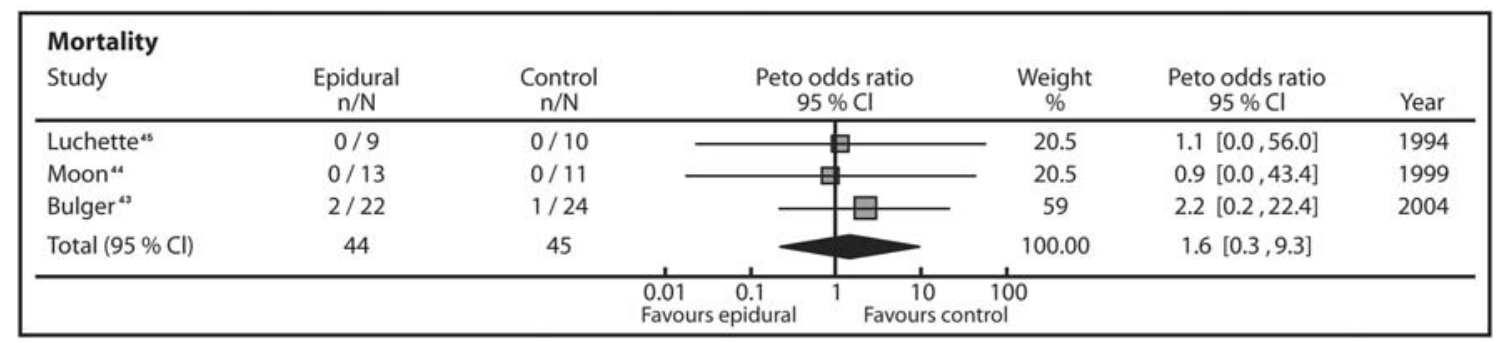

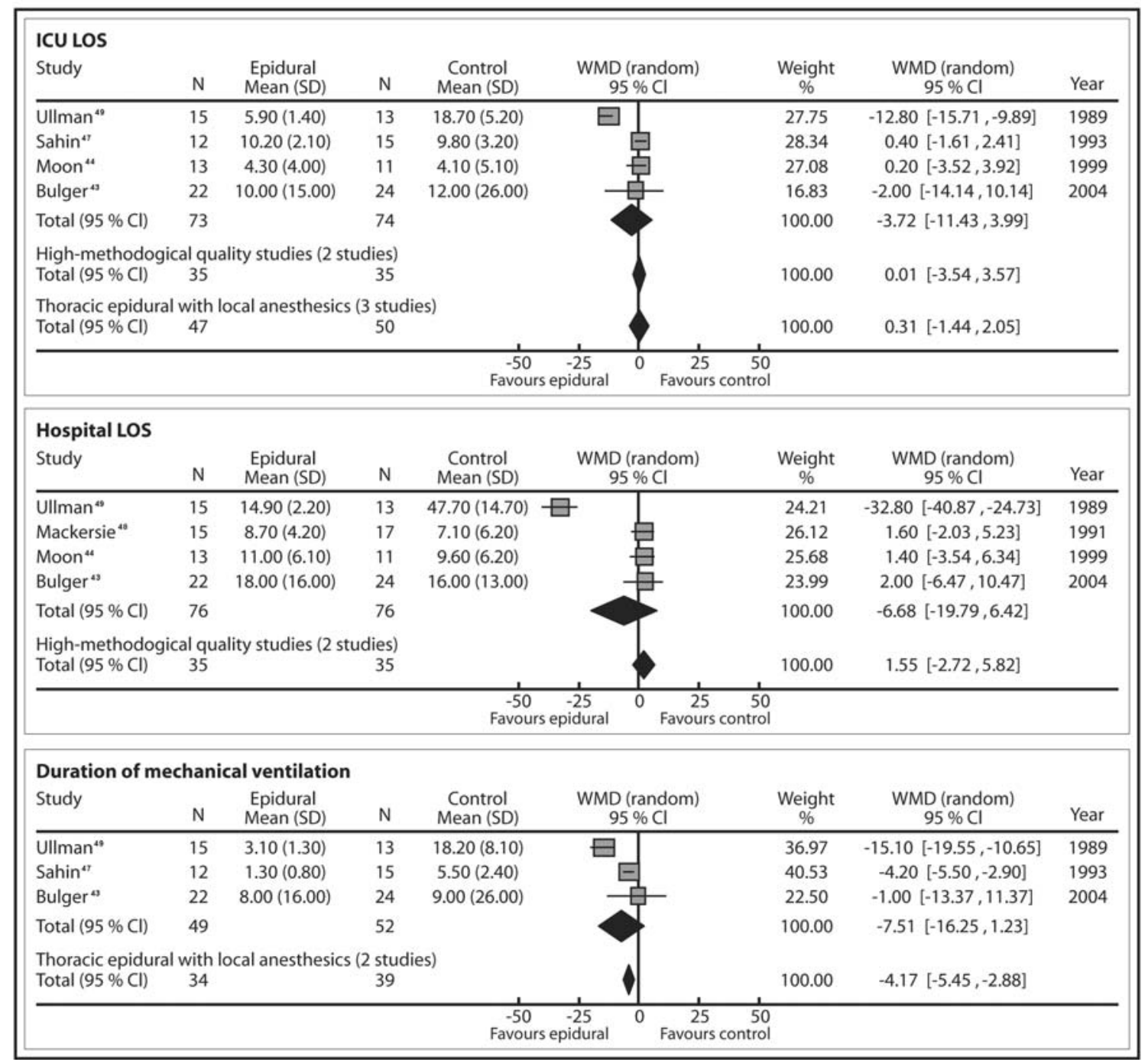

Abbreviations : LOS: Length of stay $\quad$ WMD:Weighted Mean Difference $\quad 95 \% \mathrm{CI}: 95 \%$ Confidence Interval $\quad$ SD :Standard deviations

Fig. 2 Pooled analyses of primary outcomes

modalities, hypotension was significantly associated with the use of thoracic epidural analgesia with local anesthetics (three studies, 99 patients, OR 13.76, 95\% CI [2.89, 65.51], $\left.I^{2}=0 \% \quad[P<0.01]\right) .{ }^{37-39}$ Nausea and vomiting were observed more often with parenteral opioids. ${ }^{37,42}$ Pruritus, decreased level of consciousness, and urinary retention were reported with both epidural and intravenous opioids. ${ }^{37,42,43} \mathrm{~A}$ mild allergic reaction and a superficial infection at the catheter site were reported in one patient in the epidural group. ${ }^{37}$ No study reported any serious adverse effects with the use of epidural analgesia, such as epidural hematomas, epidural abscess, spinal cord injury, or any permanent neurological symptoms. One case of respiratory depression was reported with the use of intravenous PCA. ${ }^{38}$ 


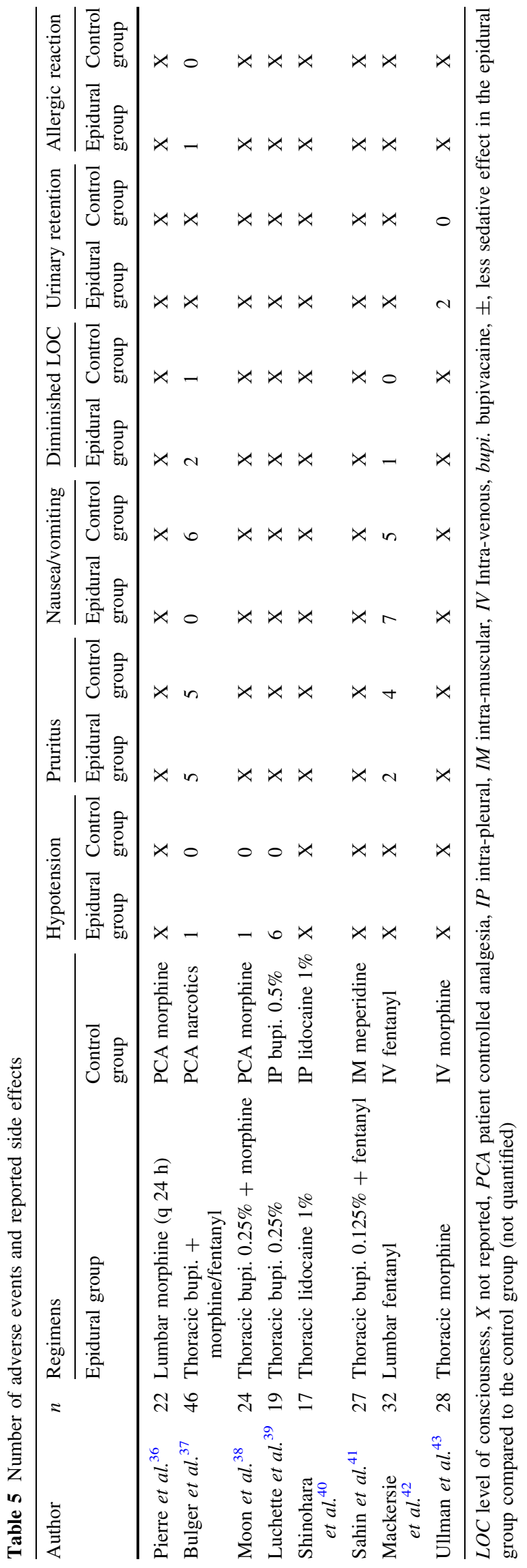

Heterogeneity

Available data from the primary studies did not allow performing additional sensitivity analyses as per the $a$ priori hypotheses. However, the observed statistical heterogeneity was explained with the sensitivity analyses performed $\left(I^{2}=0 \%\right.$ in sensitivity analyses $) .{ }^{31}$

Publication bias

Due to the small number of primary studies and the small number of participants in each study, the evaluation of potential publication bias could not be optimally performed with either visual or statistical evaluation.

\section{Discussion}

In this systematic review, epidural analgesia was not associated with significant benefits related to mortality, ICU LOS, hospital LOS, or duration of mechanical ventilation compared to other analgesic modalities in adult patients with traumatic rib fractures. When the pooled data of studies using TEA with local anesthetics were compared to other analgesic modalities or when studies of high quality methodology were analyzed on their own, consistent findings for ICU LOS and hospital LOS were observed. However, a clinically significant decrease in the duration of mechanical ventilation was observed when only pooled results of the two studies using TEA with local anesthetics were considered. Results of secondary outcomes showed potential beneficial effects with the use of epidural analgesia, such as better pain control and an improvement in some pulmonary function tests, but none of these could be evaluated in pooled analyses. Therefore, our systematic review does not provide evidence supporting the routine use of epidural analgesia compared to other analgesic modalities in adult patients with traumatic rib fractures.

Adverse effects were reported with all modalities. Hypotension was more frequent in the epidural groups when TEA with local anesthetics was used. A case of respiratory depression was reported with PCA, but no serious adverse effect was observed with epidural analgesia. This is consistent with previously published studies where serious complications of epidural analgesia were rare. $^{22-24}$ However, no study reported a systematic screening method for adverse events.

Previous review articles looked at pain management in traumatic rib fractures. In a narrative review, Karmakar et al. concluded that no specific analgesic modality could be recommended. ${ }^{11}$ These authors based their conclusions on four of the eight randomized studies included in our 
study and on retrospective and observational cohort studies. However, the findings of Karmakar et al. were consistent with those of our systematic review.

In recent clinical practice guidelines on pain management in blunt thoracic trauma, the Eastern Association for the Surgery of Trauma (EAST) stated that epidural analgesia may improve clinically significant outcomes in this population (Grade B recommendation), and it should be considered the preferred analgesic modality (Grade A recommendation). ${ }^{25}$ The results of our study do not support the strength of those recommendations. First, we were unable to demonstrate an improvement in many clinically significant outcomes with the use of epidural analgesia. Second, notwithstanding potentially superior pain control in a few studies, ${ }^{36,38,39}$ the impossibility of performing pooled data analyses for this outcome and the absence of level 1 studies would preclude the establishment of a Grade A recommendation for epidural analgesia as the preferred analgesic modality in this population. This discrepancy may be explained by performing a different assessment of the methodological quality of the studies and by including studies performed in a postoperative thoracic surgery population in the EAST guidelines.

Epidural analgesia is commonly recommended by experts in the management of patients with traumatic rib fractures. This is based mainly on evidence from studies performed in other populations of critically ill patients showing decreased pulmonary morbidity. ${ }^{18}$ On the other hand, current recommendations in a perioperative controlled setting do not favour the performance of epidural analgesia in intubated and anesthetized patients because of the suboptimal neurological evaluation due to their altered level of consciousness. ${ }^{44-46}$ Therefore, for safety reasons, epidural analgesia is relatively contraindicated in sedated patients under mechanical ventilation, a population that might potentially benefit from an improvement of their respiratory function and better pain control. Considering these recommendations and the potential for rare, but major, adverse events of this intervention, ${ }^{26,27}$ clinically significant benefits, other than better pain control, need to be demonstrated to endorse the use of epidural analgesia as a standard of care in adult patients with traumatic rib fractures. Due to its rare incidence and the lack of a systematic screening in any of the included studies, the absence of reported serious adverse events does not confirm the safety of the procedure in this population.

The main limitation of this study lies in its low statistical power shown by the wide confidence intervals of the results due to the limited number of patients included in the pooled analyses (a maximum of 75 patients per group). Another limitation of this meta-analysis relates to methodological limitations of the primary studies. Only four of the eight studies included in our review were of high methodological quality. No study was double-blinded, and the assessors in only one study were blinded to the treatment regimen. ${ }^{39}$ Moreover, co-interventions in all studies were seldom controlled. These last two limitations could have led to a treatment bias. Despite the fact that heterogeneity was explained by differences in treatment regimens and quality of methodology, further sensitivity analyses based on our a priori hypotheses could not be performed due to limited information on variables, such as age, number of fractured ribs, severity of trauma, or comorbidities. However, the exclusion criteria in most studies (spinal cord injury, depressed level of consciousness, hemodynamic instability, coagulopathy) and the relatively low ISS scores reported probably limited the influence of trauma severity on the primary outcomes. Heterogeneity might also have been underestimated secondary to a type II error due to the small number of studies.

In conclusion, in this systematic review, no reduction in mortality, ICU LOS, and hospital LOS was observed in adult patients with traumatic rib fractures with the use of epidural analgesia compared to other analgesic modalities. The duration of mechanical ventilation was reduced with the use of TEA with local anesthetics. Considering the limitations of the current literature and the rare but significant adverse events, we cannot recommend the use of epidural analgesia as a standard of care therapy in adult patients with traumatic rib fractures. However, considering the limited power of the study and the fact that we cannot exclude a beneficial effect of its use in a more specific patient population, further research is needed to identify if the use of TEA with local anesthetics is associated with clinical benefits exceeding potential harm in this population. The potential benefit of TEA on important clinical outcomes, such as incidence of nosocomial pneumonia, duration of mechanical ventilation, and ICU and hospital LOS in severely injured high-risk patients, warrant further evaluation.

Acknowledgments The authors thank the following study authors for providing additional data or for clarifying their trial methods: Drs. Bulger, Luchette, Shinohara, Pierre, and Gyurov. In particular, the authors thank Dr. Ceyla Konca for the translation of the Turkish language articles, Dr. Yoko Schreiber for the translation of the German language articles, Bob Lahav for the translation of the Hebrew language articles, Dr. Francis Grenier for the translation of the Italian language articles, and Dr. Ilia Charapov for the translation of the Russian language articles. The authors also thank Dr. Vincent Trottier for contact information, Dr. Ryan Zarychanski for statistical support, Mrs. Lucie Côté for documentation support, Mrs. Jennifer Bergeron for graphic technical support, and Mrs. Line Godin and Mrs. Amina Belcaïd for administrative assistance. Financial support: Fonds de la Recherche en Santé du Québec (FRSQ) (grant \# 015102). Dr. Turgeon is a recipient of a Clinical Research Career Award from the FRSQ.

Conflict of interest None declared. 


\section{References}

1. National Center for Health Statistics. National Ambulatory Medical Care Survey: 2004 Emergency Care Summary and Deaths: injuries 2002. www.cdc.gov/nchs. Accessed in December 2007.

2. Ziegler DW, Agarwal NN. The morbidity and mortality of rib fractures. J Trauma 1994; 37: 975-9.

3. Lee RB, Bass SM, Morris JA Jr, MacKenzie EJ. Three or more rib fractures as an indicator for transfer to a level I trauma center: a population-based study. J Trauma 1990; 30: 689-94.

4. Bulger EM, Arneson MA, Mock CN, Jurkovich GJ. Rib fractures in the elderly. J Trauma 2000; 48: 1040-6; discussion 1046-7.

5. Kerr-Valentic MA, Arthur M, Mullins RJ, Pearson TE, Mayberry $J C$. Rib fracture pain and disability: can we do better? J Trauma 2003; 54: 1058-63; discussion 1063-4.

6. Flagel BT, Luchette FA, Reed RL, et al. Half-a-dozen ribs: the breakpoint for mortality. Surgery 2005; 138: 717-23; discussion 723-5.

7. Sirmali M, Turut H, Topcu S, et al. A comprehensive analysis of traumatic rib fractures: morbidity, mortality and management. Eur J Cardiothorac Surg 2003; 24: 133-8.

8. Gann DS, Lilly MP. The neuroendocrine response to multiple trauma. World J Surg 1983; 7: 101-18.

9. $W u$ CL. Acute postoperative pain. In: Miller RD, editor. Miller's anesthesia. 6th ed. Philadelphia: Churchill Livingstone; 2005. p. 2742.

10. Kieninger AN, Bair HA, Bendick PJ, Howells GA. Epidural versus intravenous pain control in elderly patients with rib fractures. Am J Surg 2005; 189: 327-30.

11. Karmakar MK, Ho AM. Acute pain management of patients with multiple fractured ribs. J Trauma 2003; 54: 615-25.

12. Fulda GJ, Giberson F, Fagraeus $L$. A prospective randomized trial of nebulized morphine compared with patient-controlled analgesia morphine in the management of acute thoracic pain. J Trauma 2005; 59: 383-8; discussion 389-90.

13. Haenel JB, Moore FA, Moore EE, Sauaia A, Read RA, Burch JM. Extrapleural bupivacaine for amelioration of multiple rib fracture pain. J Trauma 1995; 38: 22-7.

14. Karmakar MK, Critchley LA, Ho AM, Barquist E. Continuous thoracic paravertebral infusion of bupivacaine for pain management in patients with multiple fractured ribs. Chest 2003; 123 : 424-31.

15. Wisner $D H$. A stepwise logistic regression analysis of factors affecting morbidity and mortality after thoracic trauma: effect of epidural analgesia. J Trauma 1990; 30: 799-804.

16. Wu CL, Jani ND, Perkins FM, et al. Thoracic epidural analgesia versus intravenous patient-controlled analgesia for the treatment of rib fracture pain after motor vehicle crash. J Trauma 1999; 47: 564-7.

17. Liu S, Carpenter RL, Neal JM. Epidural anesthesia, analgesia. Their role in postoperative outcome. Anesthesiology 1995; 82: 1474-506.

18. Ballantyne JC, Carr DB, de Ferranti $S$, et al. The comparative effects of postoperative analgesic therapies on pulmonary outcome: cumulative meta-analyses of randomized, controlled trials. Anesth Analg 1998; 86: 598-612.

19. Rigg JR, Jamrozik K, Myles PS, et al. Master Anaesthesia Trial Study Group. Epidural anaesthesia and analgesia and outcome of major surgery: a randomised trial. Lancet 2002; 359: 1276-82.

20. Liu SS, $W u C L$. Effect of postoperative analgesia on major postoperative complications: a systematic update of the evidence. Anesth Analg 2007; 104: 689-702.

21. Nishimori M, Ballantyne JC, Low JH. Epidural pain relief versus systemic opioid-based pain relief for abdominal aortic surgery. Cochrane Database Syst Rev 2006; 3: CD005059.
22. Moen V, Dahlgren N, Irestedt L. Severe neurological complications after central neuraxial blockades in Sweden 1990-1999. Anesthesiology 2004; 101: 950-9.

23. Mayall $M F$, Calder I. Spinal cord injury following an attempted thoracic epidural. Anaesthesia 1999; 54: 990-4.

24. Tay SM, Lee R. Case report: catheter-related epidural abscess. Ann Acad Med Singapore 2001; 30: 62-5.

25. Simon BJ, Cushman J, Barraco R, et al. EAST Practice Management Guidelines Work Group. Pain management guidelines for blunt thoracic trauma. J Trauma 2005; 59: 1256-67.

26. Kindler $\mathrm{CH}$, Seeberger MD, Staender SE. Epidural abscess complicating epidural anesthesia and analgesia. An analysis of the literature. Acta Anaesthesiol Scand 1998; 42: 614-20.

27. Kvalsvik O, Borchgrevink PC, Gisvold SE. Epidural abscess following continuous epidural analgesia in two traumatized patients. Acta Anaesthesiol Scand 1998; 42: 732-5.

28. Jadad AR, Moore RA, Carroll D, et al. Assessing the quality of reports of randomized clinical trials: is blinding necessary? Control Clin Trials 1996; 17: 1-12.

29. Schulz KF. Assessing allocation concealment and blinding in randomized controlled trials: why bother? ACP J Club 2000; 132: A11-2.

30. DerSimonian R, Laird N. Meta-analysis in clinical trials. Control Clin Trials 1986; 7: 177-88.

31. Higgins JP, Thompson SG, Deeks JJ, Altman DG. Measuring inconsistency in meta-analyses. BMJ 2003; 327: 557-60.

32. Bolliger CT, Van Eeden SF. Treatment of multiple rib fractures. Randomized controlled trial comparing ventilatory with nonventilatory management. Chest 1990; 97: 943-8.

33. Gyurov E, Milanov S, Milanov M. Intrapleural versus epidural analgesia with local anesthetics in patients with thoracic trauma. Critical Care 2004; 8: P245.

34. Cicala RS, Voeller GR, Fox T, Fabian TC, Kudsk K, Mangiante $E C$. Epidural analgesia in thoracic trauma: effects of lumbar morphine and thoracic bupivacaine on pulmonary function. Crit Care Med 1990; 18: 229-31.

35. Vagner EA, Zaugol'nikov VS, Plaksin SA, Torbin VV, Matveev $A T$. Effect of peridural analgesia on blood gas composition and central hemodynamics in patients with closed trauma of the chest (Russian). Vestn Khir Im I I Grek 1985; 135: 100-1.

36. Pierre EJ, Martin P, Frohock JM, et al. Lumbar epidural morphine versus. Patient-controlled analgesia morphine in patients with multiple rib fractures. Anesthesiology 2005; 103: A289.

37. Bulger EM, Edwards T, Klotz P, Jurkovich GJ. Epidural analgesia improves outcome after multiple rib fractures. Surgery 2004; 136 : 426-30.

38. Moon MR, Luchette FA, Gibson SW, et al. Prospective, randomized comparison of epidural versus parenteral opioid analgesia in thoracic trauma. Ann Surg 1999; 229: 684-91; discussion 691-2.

39. Luchette FA, Radafshar SM, Kaiser R, Flynn W, Hassett JM. Prospective evaluation of epidural versus intrapleural catheters for analgesia in chest wall trauma. J Trauma 1994; 36: 865-9; discussion 869-70.

40. Shinohara K, Iwama H, Akama $Y$, Tase $C$. Interpleural block for patients with multiple rib fractures: comparison with epidural block. J Emerg Med 1994; 12: 441-6.

41. Sahin $S$, Uckunkaya N, Soyal $S$, et al. The role of epidural continuous pain treatment on duration of intubation, ventilation and ICU stay in flail chest patients. Agri Dergisi 1993; 5: 18-20. (in Turkish).

42. Mackersie RC, Karagianes TG, Hoyt DB, Davis JW. Prospective evaluation of epidural and intravenous administration of fentanyl for pain control and restoration of ventilatory function following multiple rib fractures. J Trauma 1991; 31: 443-9; discussion 449-51. 
43. Ullman DA, Fortune JB, Greenhouse BB, Wimpy RE, Kennedy TM. The treatment of patients with multiple rib fractures using continuous thoracic epidural narcotic infusion. Reg Anesth 1989; 14: 43-7.

44. Bromage PR, Benumof JL. Paraplegia following intracord injection during attempted epidural anesthesia under general anesthesia. Reg Anesth Pain Med 1998; 23: 104-7.
45. Krane EJ, Dalens BJ, Murat I, Murrell D. The safety of epidurals placed during general anesthesia. Reg Anesth Pain Med 1998; 23 : 433-8.

46. Rosenquist RW, Birnbach DJ. Epidural insertion in anesthetized adults: will your patients thank you? Anesth Analg 2003; 96: 1545-6. 